\title{
Air plasma sprayed thermal barrier coatings on titanium alloy substrates
}

\author{
Hong Zhou*, Fei Li, Bo He, Jun Wang, Bao-de Sun \\ State Key Laboratory of Metal Matrix Composites, Shanghai Jiao Tong University, 1954 Huashan Road, Shanghai 200030, PR China
}

Received 7 December 2006; accepted in revised form 1 February 2007

Available online 14 February 2007

\begin{abstract}
Titanium alloys as lightweight structure materials have been shown more interest in the use at moderately elevated temperatures. However, their poor oxidation resistance at temperature above $600{ }^{\circ} \mathrm{C}$ limits a wide application. Consequently, thermal protection becomes a concern. 8 wt. $\%$ yttria partially stabilized zirconia thermal barrier coatings (TBCs) were air plasma sprayed on titanium alloy substrates (Ti-6.6Al-3.61Mo$1.69 \mathrm{Zr}-0.28 \mathrm{Si}$ in wt.\%). The microstructures and mechanical properties of the coating system were studied by using SEM, XRD, MIP, tensile test and Vickers microhardness. The results show that the as-sprayed ceramic coating consists of the non-transformable tetragonal $t^{\prime}$ phase of zirconia. The microstructure of the internal substrate keeps unchanged, no reaction and interdiffusion happen obviously at the bond coat/substrate interface during plasma spraying. However, there exists a thin layer of plastic deformation zone in the substrate beneath the bond coat/substrate interface. The surface connected porosity of the as-sprayed ceramic coating shows a typical bimodal pore size distribution. The adhesive strength of the TBCs decreases with increasing the thickness of the as-sprayed ceramic coatings, which is attributed to the residual stresses induced during thermal spraying. The anisotropy in the mechanical properties between the cross section and the top surface of the ceramic coatings is examined. (C) 2007 Elsevier B.V. All rights reserved.
\end{abstract}

Keywords: Thermal barrier coatings; Titanium alloys; Mechanical properties; Microstructure

\section{Introduction}

Titanium and its alloys play important roles in new structural materials. The applications of titanium are mainly focused on its high specific strength at room and elevated temperatures, unique corrosion resistance and nonmagnetic properties. This fact has predetermined the wide use of its alloys in aircraft and space industries. However, poor oxidation resistance and oxygen induced embrittlement deteriorate the application of titanium alloy at high temperatures. This poor oxidation resistance results from the formation of a non-protective oxide scale consisting of a heterogeneous mixture of alumina and titania on high temperature exposure [1]. Deposition of protective and thermally insulating coatings is considered as an effective means to reduce the substrate temperature and suppress both oxidation and oxygen induced embrittlement. Research work in the past decades showed that it was a more effective method by the protective coatings to provide im-

\footnotetext{
* Corresponding author. Tel.: +86 21 62933163; fax: +86 2162932870 . E-mail addresses: Zhou7210@yahoo.com.cn, zhouhong@sjtu.edu.cn (H. Zhou).
}

proved oxidation resistance to titanium alloys than by alloying [2-5].

Thermal barrier coatings (TBCs) have been widely used to provide thermal protection to metallic components from the hot gas stream in gas-turbine engines used for aircraft propulsion, power generation and marine propulsion due to their low thermal conductivity and thermal diffusivity combined with proper chemical stability at high temperatures. Conventional thermal barrier coatings usually consist of a layer of low thermal conductivity ceramic coating which is commonly a yttria partially stabilized zirconia (YPSZ) coating fabricated by plasma spraying or electron beam physical vapor deposition, and a layer of MCrAlY $(\mathrm{M}=\mathrm{Ni}, \mathrm{Co}, \mathrm{Fe})$ bond coat. The TBC system allows conventional metals to be reliably used at high temperatures because the ceramic layer provides thermal stability to the base metal due to insulation from the heat, while the metallic bond coat provides oxidation resistance, and sufficient toughness [6-8]. Consequently, a shortcut to improve the short-term properties of the titanium alloy at high temperatures is through plasma spraying thermal barrier coatings on titanium alloy substrates. Braun et al. investigated the performance of thermal barrier coatings on $\gamma$-TiAl, and found 
that zirconia top coat offered a promising thermal protection concept to be applied on the alloy [9]. Mckee et al. investigated the plasma sprayed coating for titanium alloy oxidation protection, the ductile coatings of $\mathrm{MCr}$ and MCrAlY type were found to confer protection against oxidation and embrittlement for hundreds of hours during rapid thermal cycling in flowing air to at least $850^{\circ} \mathrm{C}$ [3]. Tang et al. found that MCrAlY coatings could remarkably improve the oxidation resistance of TiAl owning to the formation of protective $\mathrm{Al}_{2} \mathrm{O}_{3}$ scale [10].

In the present work, $8 \mathrm{wt} . \%$ yttria partially stabilized zirconia coatings were air plasma sprayed on titanium alloy substrates, their microstructures and mechanical properties after plasma spraying were investigated. The purpose of the research is to study the effect of plasma spraying on the titanium alloy, and the microstructures, mechanical properties of the as-sprayed thermal barrier coatings on the titanium alloy.

\section{Experimental}

\subsection{Sample preparation and coating}

An annealed state titanium alloy rod (Ti-6.6Al-3.61Mo$1.69 \mathrm{Zr}-0.28 \mathrm{Si}$ in wt.\%) with diameter of $80 \mathrm{~mm}$ was used as the substrate material. Commercially available YPSZ $\left(\mathrm{ZrO}_{2}-\right.$ 8 wt.\% $\mathrm{Y}_{2} \mathrm{O}_{3}$ ) ceramic feedstock powder (HHZrO8, Chinese Academy of Agricultural Mechanization Sciences, Beijing, China) with particle sizes ranging from 38.5 to $63 \mu \mathrm{m}$ and $\mathrm{Ni}-$ 20Cr-6Al-Y metal powder (HHNiCrAlY-9, Chinese Academy of Agricultural Mechanization Sciences, Beijing, China) with particle sizes ranging from 10 to $100 \mu \mathrm{m}$ were used.

The titanium alloy rod was cut into disks $(\Phi 80 \times 3 \mathrm{~mm})$ as the substrates by a wire cutting machine. After finally polished to 400 mesh abrasive, the substrates were grit blasted with alumina, ultrasonically cleaned in anhydrous ethylene alcohol and dried in cold air prior to coating deposition. A NiCrAlY bond coat of about $100 \mu \mathrm{m}$ in thickness was air plasma sprayed onto the substrate before a $300 \mu \mathrm{m}$ YPSZ top coat was deposited by using the same air plasma spray system (DH80, Chinese Academy of Agricultural Mechanization Sciences, Beijing, China). No air cooling on the back side of the substrates was applied during the spraying process. The temperatures of the substrate backside were measured with an infrared thermometer (F68, FLUKE, USA) during the spraying process. The spraying parameters are given in Table 1.

Table 1

The spraying parameters for the TBCs

\begin{tabular}{|c|c|c|}
\hline & NiCrAlY & YPSZ \\
\hline Current, A & 480 & 510 \\
\hline Voltage, $\mathrm{V}$ & 65 & 75 \\
\hline Primary gas, $\mathrm{Ar}, 1 \mathrm{~min}^{-1}$ & 37 & - \\
\hline Primary gas, $\mathrm{N}_{2}, 1 \mathrm{~min}^{-1}$ & - & 37 \\
\hline Secondary gas, $\mathrm{H}_{2}, 1 \mathrm{~min}^{-1}$ & 5 & 5 \\
\hline Powder feeding rate, $\mathrm{g} \mathrm{min}-1$ & 50 & 15 \\
\hline Torch traverse speed, $\mathrm{mm} \mathrm{s}^{-1}$ & 10 & 6 \\
\hline Substrate rotation speed, rpm & 126 & 126 \\
\hline Stand off distance, $\mathrm{mm}$ & 100 & 60 \\
\hline
\end{tabular}

a)
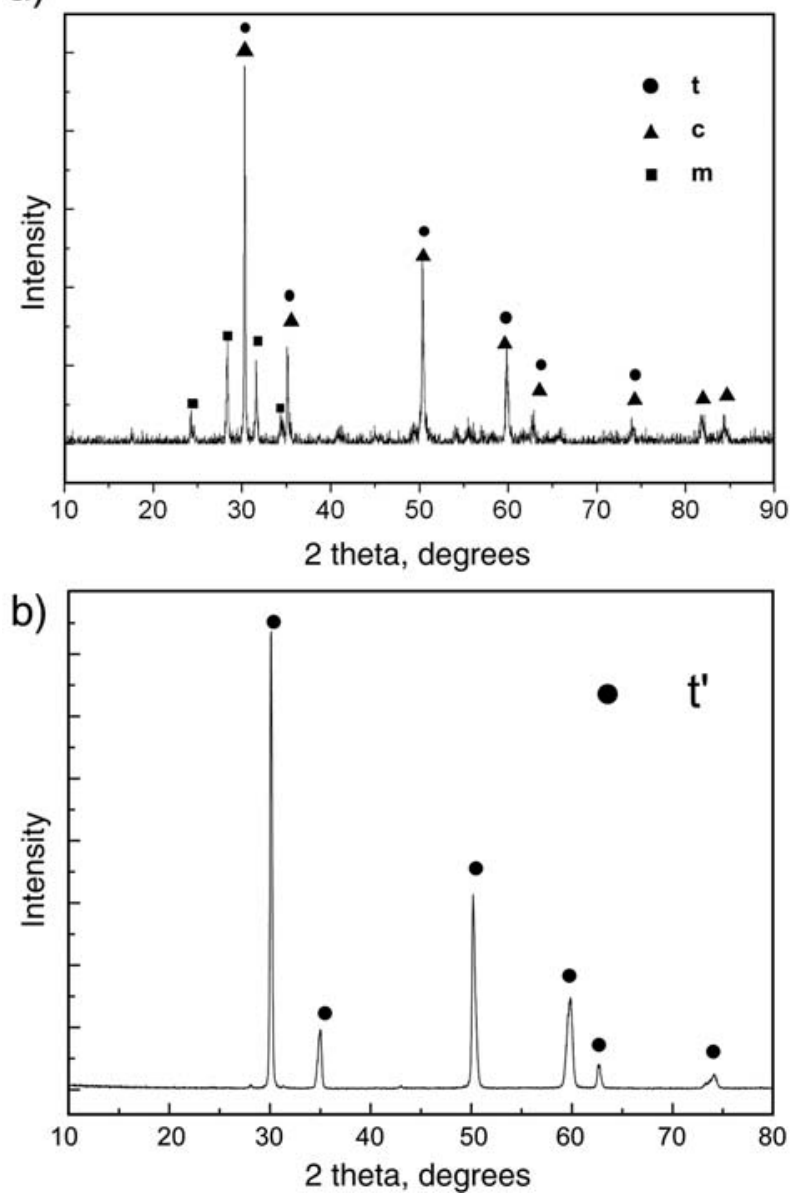

Fig. 1. XRD patterns of (a) the feedstock powder and (b) the as-sprayed ceramic coating.

\subsection{Microstructure observation and property tests}

Surface connected porosity of the as-sprayed ceramic coating was determined by a mercury intrusion porosimeter (MIP, poresizer9320, Micrometitics Instrument Corporation, Norcross, USA). Free standing YPSZ coating specimens were produced by removing substrates from coatings with hydrochloric acid solution. In order to avoid the effect of surface roughness, the surfaces of the specimen were finely polished before measurement. The microstructures of the substrates and the TBCs were investigated by using a field emission scanning electron microscope (FESEM, Model FEI Sirion 200, USA) and a Leco-I32A image analysis system (LECO Corporation, St. Joseph, USA). An energy dispersive X-ray spectroscopy (EDS, Oxford INCA, UK) was used to detect the chemical compositions on a microscopic scale. Phase transformations were studied using a X-ray diffractometer (XRD, Bruker, model D8, Germany) with $\mathrm{CuK}_{\alpha}$ radiation at $40 \mathrm{kV}$ and $30 \mathrm{~mA}$, the scanning speed of $2 \theta$ was $4^{\circ} \mathrm{min}^{-1}$ when measuring.

Microhardness test was performed using a Vickers indentor (HXD-1000A, Shanghai, China) with loads of $50 \mathrm{~g}$ and $100 \mathrm{~g}$ for $15 \mathrm{~s}$ for the as-sprayed ceramic coatings and the substrates, respectively. The cross sections and the top surfaces of the ceramic coatings were polished before indentations and the 

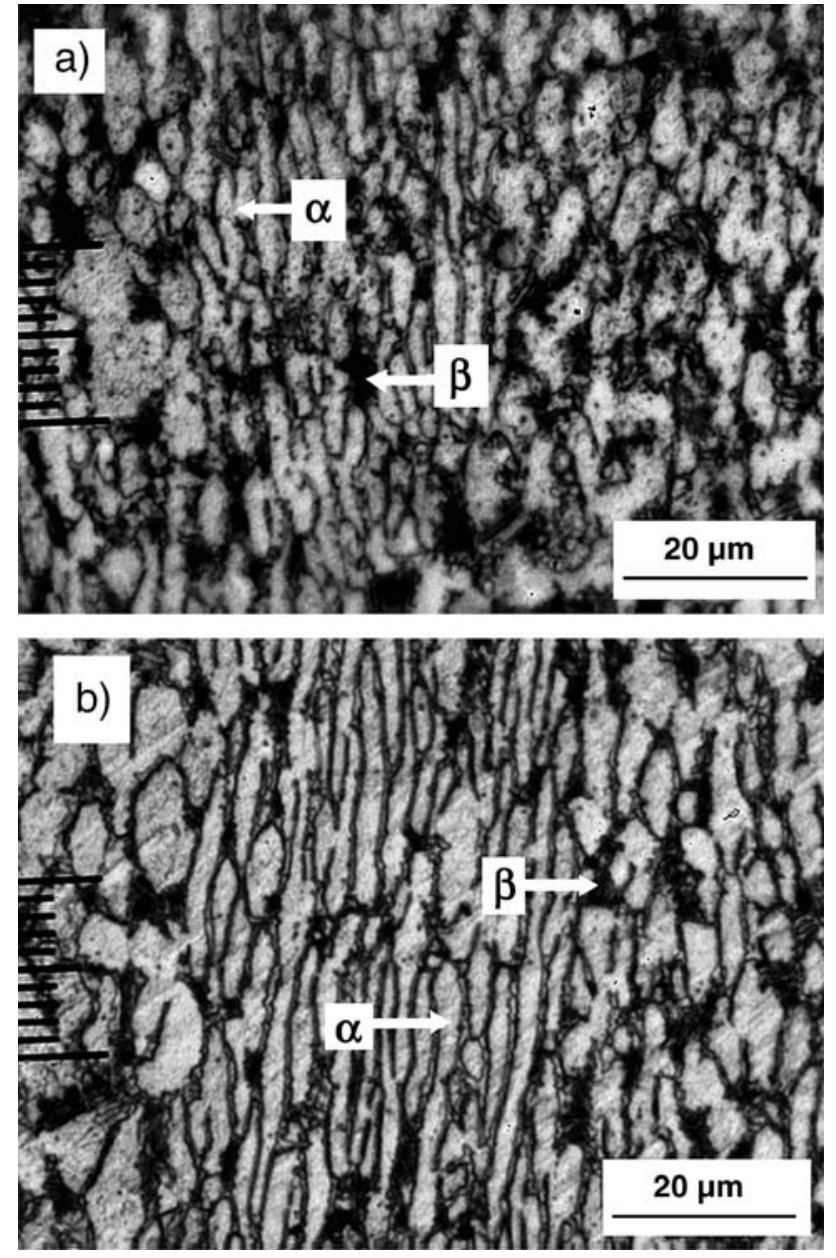

Fig. 2. The microstructures of the internal substrate a) before and b) after air plasma spraying.

distance between two indentations was at least three times the diagonal to prevent stress-field effects from nearby indentations. The microhardness value for the substrate was taken from the average value of all measurements. 10 measurement points which were evenly distributed along the thickness of the substrate were selected to observe the variation of microhardness of the substrate. 20 measurements were conducted for a Weibull analysis of the ceramic coating since the hardness distribution of the brittle ceramic can be highly skewed or broadly distributed. The Weibull distribution has the merit in being simple to accommodate this problem, and has been used widely to describe a wide range of problems including the mechanical properties of brittle materials and lifetime testing. It is based on 'the weakest link hypothesis' which means that the most serious flaw controls the strength. The two-parameter Weibull distribution is given as

$F(x)=1-\exp \left[-\left(\frac{x}{x_{0}}\right)\right]^{m}$

where $F(x)$ is the cumulative density function of probability, $x$ is the microhardness data used, $x_{0}$ is the characteristic value below which $63.2 \%$ of the data lie, and $m$ is the Weibull modulus. The parameters of the Weibull distribution are the
Weibull modulus, $m$, which reflects the data scatter within the distribution, and the scale factor, $x_{0}$, which gives $63.2 \%$ of the cumulative density. The Weibull plot was used to determine the desired Weibull parameters. The Eq. (1) can be written as

$\ln \ln [1 /(1-F(x))]=m\left[\ln (x)-\ln \left(x_{0}\right)\right]$

Thus, a plot of $\ln \ln [1 /(1-F(x))]$ versus $\ln (x)$ will yield a straight line if the Weibull model is appropriate. The value of $F$ $(x)$ is obtained from placing the data in ascending order and letting

$F(x)=\frac{i-0.5}{n}$

where $n$ is the total number of data points, and $i$ is the $i$ th order in ascending data set [11-13].

The adhesion tensile tests were conducted to measure the adhesive strength of the TBCs samples using an Instron universal material test system (Modal 1255, Instron, UK) with drawing rate of $1 \mathrm{~mm} \mathrm{~min}^{-1}$. The titanium alloy rod was machined into cylinders with dimension of $\Phi 40 \times 40 \mathrm{~mm}$ in accordance with GB8642-88. The same TBC materials and spraying conditions as those for the disk substrates were used for the cylindrical samples. The opposite of the couple for the tensile test was made of mild carbon steel with the same dimension as the titanium alloy cylindrical samples. The pair was glued together with E-7 epoxy resin on the top surface, fully cured in an autoclave and kept for $24 \mathrm{~h}$ before tensile testing. TBCs with three different ceramic coating thicknesses, $0.2 \mathrm{~mm}, 0.3 \mathrm{~mm}$, and $0.4 \mathrm{~mm}$, were plasma sprayed on the titanium alloy samples respectively in order to observe the effect of ceramic thickness on the adhesive strength of the coatings.

\section{Results and discussion}

\subsection{Phase determination of the ceramic coating via XRD}

The phase composition results of X-ray diffraction analysis of the ceramic feedstock powder and the as-sprayed ceramic

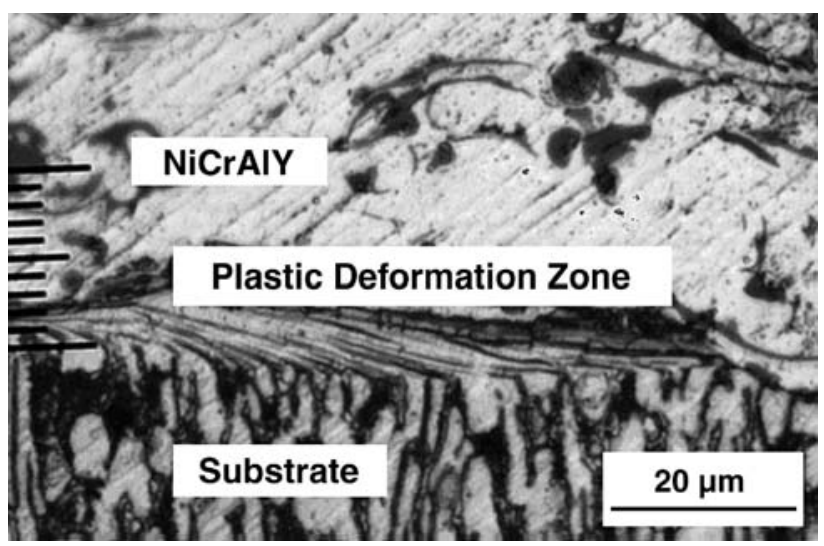

Fig. 3. The thin layer of plastic deformation zone in the substrate surface after air plasma spraying. 

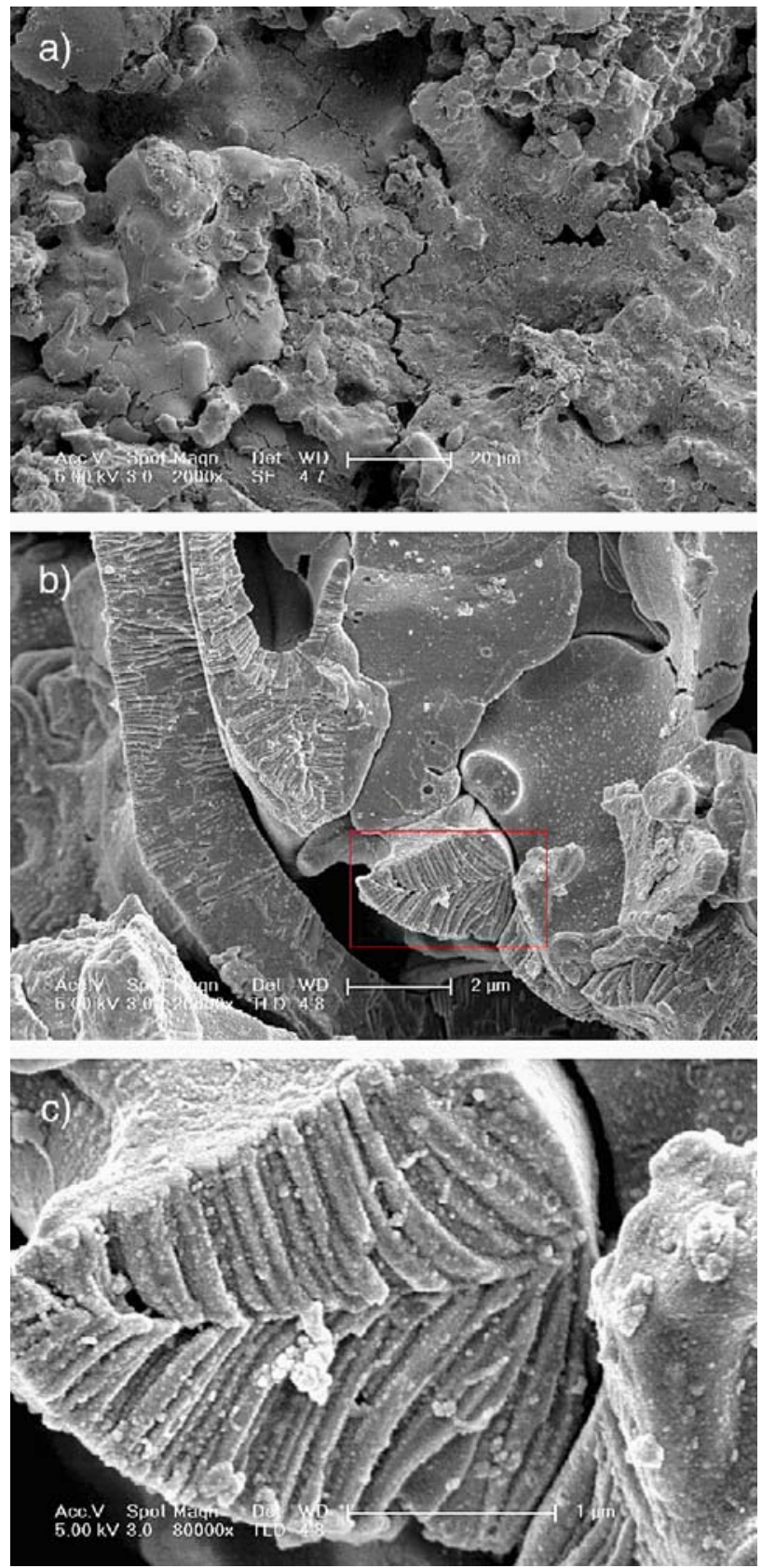

Fig. 4. SEM micrographs of a) the top surface and b), c) the fractured cross section of the ceramic layer.

coating are shown in Fig. 1. From the XRD patterns, it can be found that the powder is composed of tetragonal, cubic and monoclinic phases, whereas the ceramic coating exhibits only a presence of the non-transformable tetragonal $t^{\prime}$ phase of zirconia, no monoclinic phase is found. The metastable tetragonal $\mathrm{t}^{\prime}$ phase is typical of thermally sprayed zirconia, which is formed due to quenching of droplet after impacting on the substrate during plasma spraying. The metastable tetragonal $\mathrm{t}^{\prime}$ phase does not undergo the detrimental tetragonal to monoclinic transformation that is related with large stresses (volume expansion of $\sim 4 \%$ ). Therefore the $t^{\prime}$ phase is stable during thermal cycling at the $\mathrm{t}-\mathrm{m}$ phase transformation temperature. The $\mathrm{t}^{\prime}$ reverts into the equilibrium tetragonal $\mathrm{t}$ and cubic $\mathrm{c}$ phases during high temperature exposures. However the cation-diffusion controlled transformation is found to be sluggish at temperatures below $120{ }^{\circ} \mathrm{C}$ [14]. In contrast to the $t^{\prime}$ phase, the equilibrium phase $t$ which results from a very slow approach to phase equilibration, undergoes the $\mathrm{t}-\mathrm{m}$ transformation that limits the lifetime of the TBCs. Mechanical properties and lifetime are optimized when the maximum amount of the metastable tetragonal $\mathrm{t}^{\prime}$ phase can be obtained by the plasma spraying process for the rapid solidification.

\subsection{Microstructures of the substrate and the TBCs}

The substrate, which is an $\alpha+\beta$ type titanium alloy, can be used for long term at the temperature of $500{ }^{\circ} \mathrm{C}$. Fig. 2 shows the microstructures of the substrate before and after plasma spraying. It reveals that the substrate is composed of the $\alpha$ phase with equiaxed grains and elongated grains, and the $\beta$ phase which is distributed along the grain boundaries of $\alpha$ phase. The $\alpha$ phase constitutes the dominative structure, representing more than $70 \%$ of the volume fraction of the substrate, as obtained by using the image analysis system. There are no obvious changes of microstructure taken place inside the substrate after plasma spraying by comparison of the microstructures of the substrates, as observed in Fig. 2. It results from the short period of heating on the substrate and the moving of the spray gun during plasma spraying, which made the substrates stay at low temperatures,
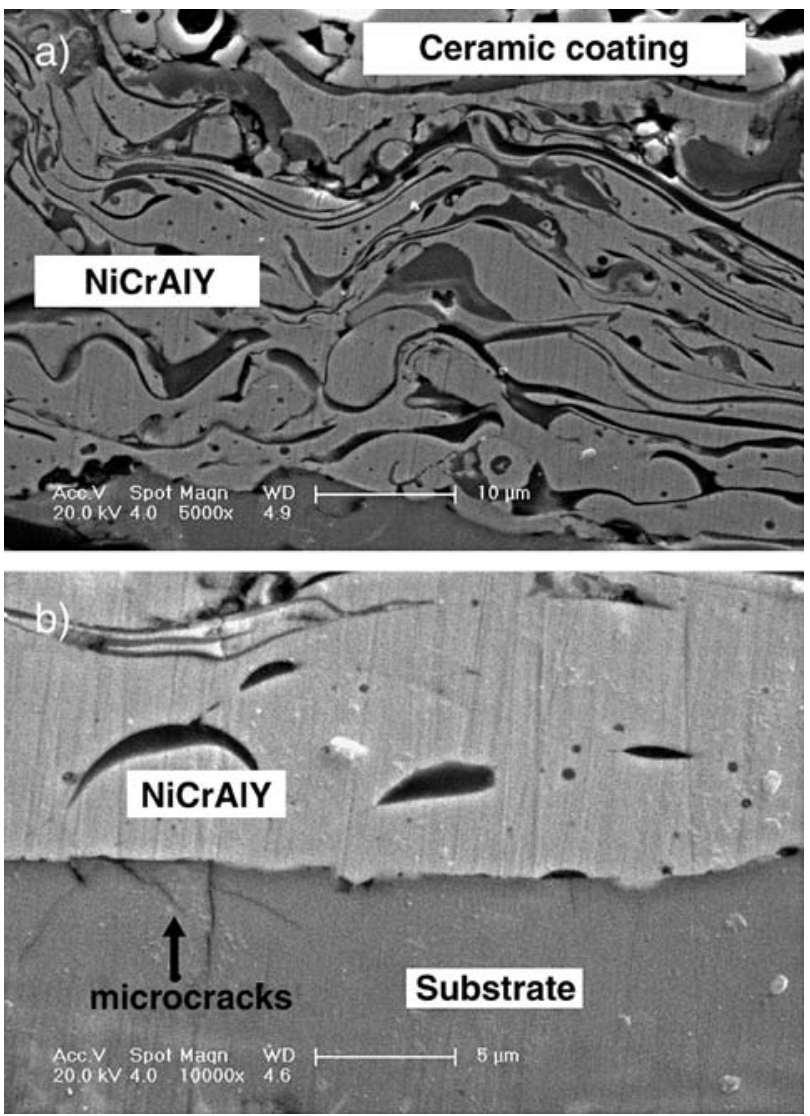

Fig. 5. SEM cross-sectional microstructures of the polished as-sprayed coating. a) The bond coat; b) The bond coat/substrate interface. 
and keep the microstructure intact. The measured highest surface temperature on the disk backside during plasma spraying was $620{ }^{\circ} \mathrm{C}$. The phase transformation temperature for this titanium alloy is $1000 \pm 20{ }^{\circ} \mathrm{C}$ [15]. Therefore the microstructure of the internal substrate keeps unchanged after plasma spraying.

However, the surface of the substrate beneath the bond coat/ substrate interface shows a different morphology in contrast to the internal substrate. A thin layer of plastic deformation zone exists evidently in the substrate surface, as shown in Fig. 3. The grains in the zone turn deformed to one direction with a riverlike microstructure along the bond coat/substrate interface. It may be explained that during plasma spraying, the feedstock particles were sent and heated to above their melting point in the plasma jet. Next, the molten droplets with high temperatures were accelerated and impacted upon the rotating substrate surface which was moving normal to the plasma gun with a relative velocity in order to get a fully sprayed surface, and then passed the heat flux to the substrate surface, which could increase the transient temperature of the substrate surface to a high level. On the other hand, the substrate with $3 \mathrm{~mm}$ thick- ness, which was stiff and tough enough to prevent the disk from deformation during plasma spraying, limited the heat conduction through the substrate, and helped increase its own temperature. Thus, the substrate surface was led to a nearmolten state. With the cooperation of the impacting of high speed molten droplets from one certain direction and the low deformation resistance of the substrate surface at high temperatures, the plastic deformation zone beneath the bond coat/substrate interface was formed. The thickness of the plastic deformation layer is non-uniform, as seen in Fig. 3. This phenomenon is related with the flattening ability of molten droplet and the inhomogeneous distribution of molten droplets during plasma spraying. The molten droplets got flattened after impinging on the substrate. However, the thickness of the flattened droplet was uneven with a thick core, and a thin brim. Therefore, the core with more heat would produce a thick plastic deformation zone, vice versa. The inhomogeneous distribution of molten droplets made the contact areas and heat flux randomly distributed and resulted in the variation of thickness of the plastic deformation zone in the surface. In addition, the physical contact between the splat and the substrate

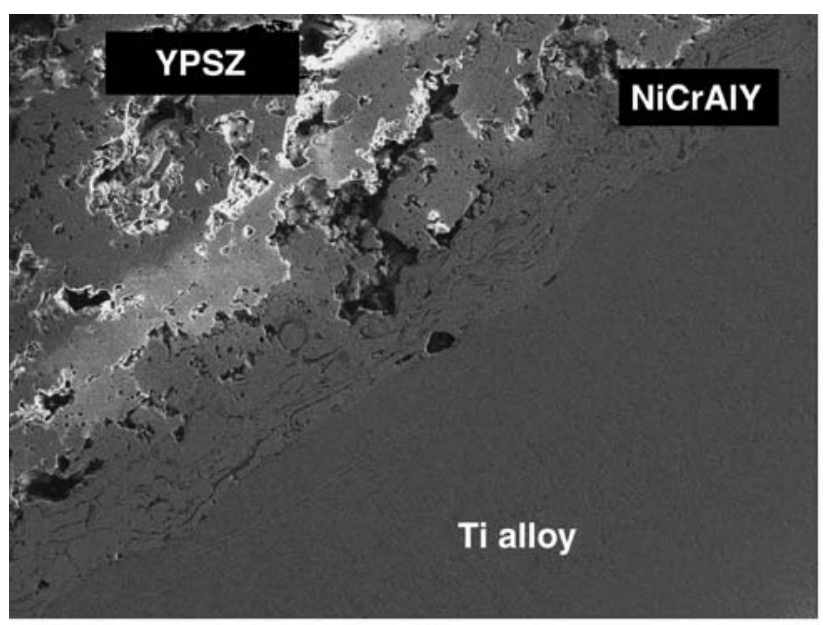

$100 \mu \mathrm{m}$

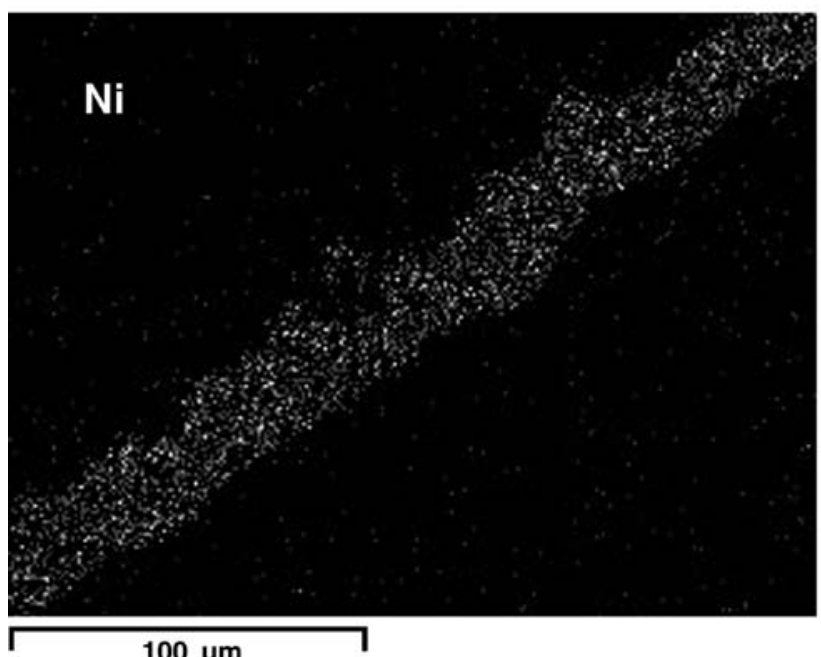

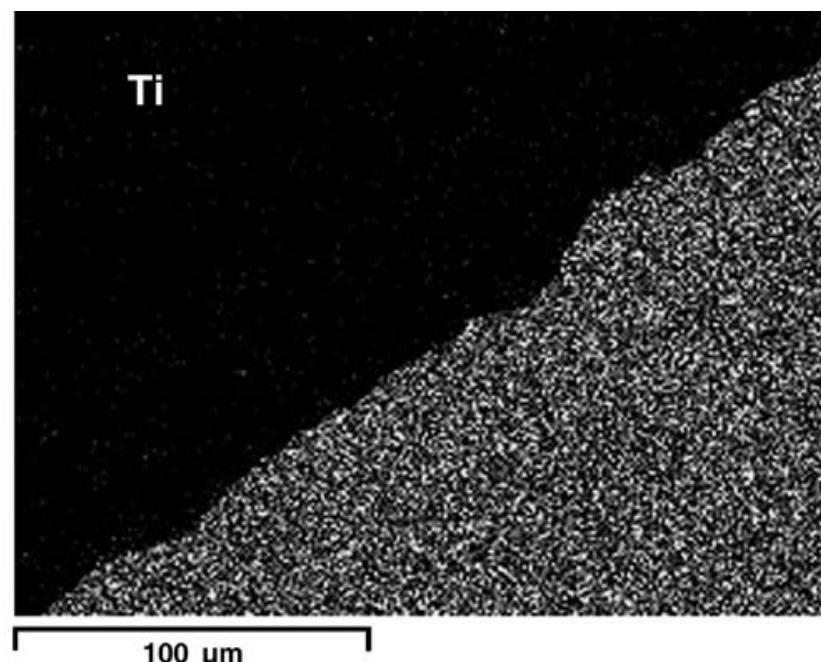

$100 \mu \mathrm{m}$

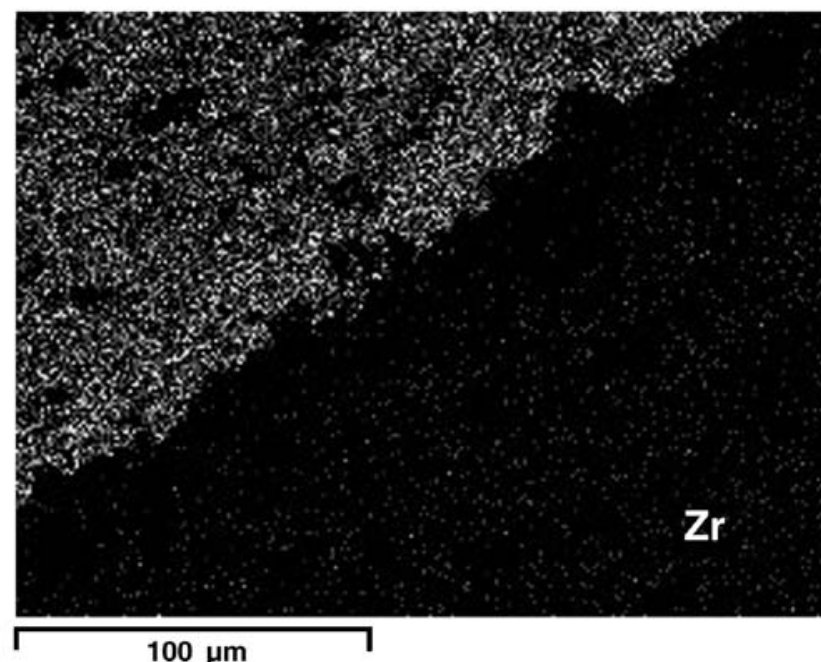

$100 \mu \mathrm{m}$

Fig. 6. SEM morphology and element area distributions around the bond coat/substrate interface after plasma spraying. 
a)

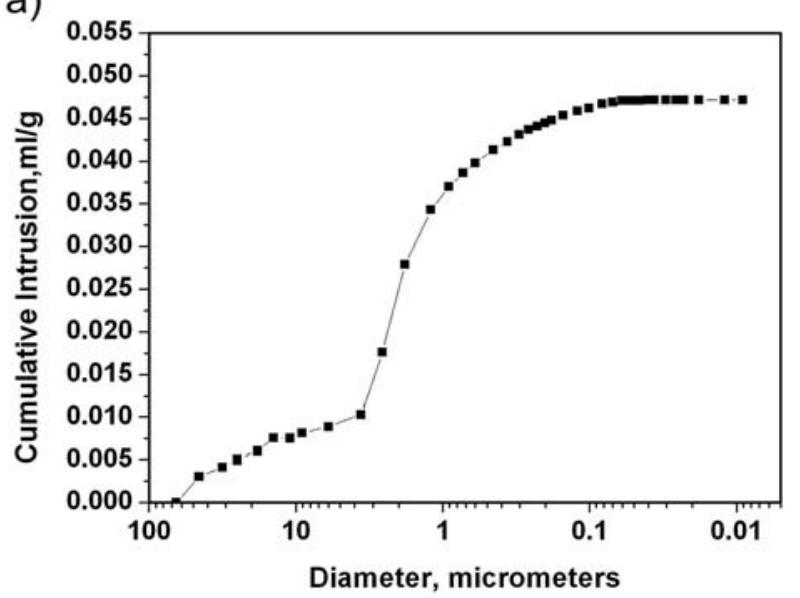

b)

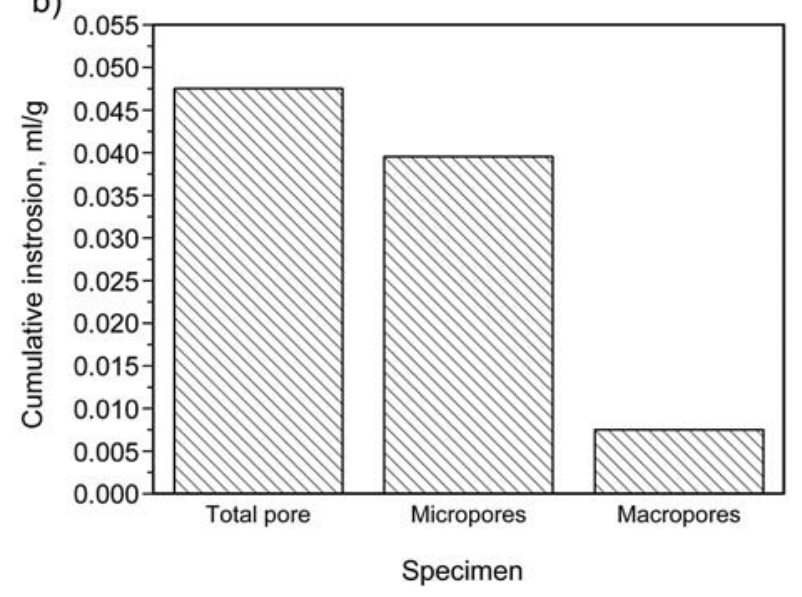

Fig. 7. Porosity distribution of the as-sprayed ceramic coating, a); and compositions of the total porosity, b).

is sometimes limited to several contact points, which also leads to the non-uniform thickness of the plastic deformation layer. Moreover, the spraying velocity and the scanning velocity also have an effect on the variation of thickness because they are connected with the energy input to the substrate.

Fig. 4 shows the SEM morphologies of the YPSZ top coating surface and the fractured cross section. There exist many microcracks which are perpendicular to the substrate in the top ceramic, as may be explained that the cooling rate was very rapid during thermal spraying, and hence induced residual stresses in the coating which resulted in the microcracks. The fractured cross section of the as-sprayed ceramic coating shows a typical lamellar structure in an overlapping and interlocking fashion. The contact and adhesion between laminas are relatively weak because of the microcracks, micropores and the discontinuous solidification process inherent in plasma spraying. As a matter of fact, the true contact area between splats is often a very limited percentage of the splat area. The laminas with thickness of about 2-4 $\mu \mathrm{m}$ have a nanosized columnar microstructure due to the rapid heterogeneous nucleation occurring at the cooler boundaries of the flattened droplets at large undercooling. Many pores including those in the splats or among splats are observed in the ceramic coating.
The cross-sectional microstructure of the polished plasma sprayed coating system is shown in Fig. 5. The bond coat also has a lamellar structure with microcracks and pores, as seen in Fig. 5a. The grey parts between the splats in the bond coat show a higher concentration of $\mathrm{Al}$ and $\mathrm{O}$, as detected by EDS. The oxidation of the bond coat resulted from the interaction of the molten particles with the surrounding atmosphere being pulled into the spray jet during the plasma spraying as well as the selective oxidation of $\mathrm{Al}$ element. The undulated interfaces related with the bond coat are clearly observed. The undulation is favorable for adhesion of the interface by increasing the mechanical anchoring. However, it often induces imperfection and microcracks and tensile stresses vertical to the interface, which causes the eventual failure of TBCs. Several microcracks are observed in the substrate beneath the bond coat/substrate interface, as shown in Fig. 5b. The reason may be that the tensile stresses were generated on the substrate surface when the interface which was hotter than the internal substrate cooled down more slowly from high temperatures during thermal spraying. When the maximum tensile stress was larger enough, the microcracks were initiated and propagated. Meanwhile, the existence of a thermal expansion coefficient mismatch of different materials also caused the crack formation. Fig. 6 shows the element area distributions around the bond coat/substrate interface after plasma spraying. It can be seen that the element distributions of $\mathrm{Zr}, \mathrm{Ni}$ and $\mathrm{Ti}$ have clear edges at the interfaces within the region and the atomic diffusion between different materials does not take place evidently because of the short time at high temperature during plasma spraying. Moreover, the ceramic has a different chemical bond with the metal. As a result, the interlocking mechanism is the main reason for the coating adhesion.

\subsection{Porosity of the ceramic coating}

The measured surface connected porosity of the as-sprayed ceramic coating is $15.08 \%$ with a median pore diameter in volume of $1.877 \mu \mathrm{m}$. Fig. 7a shows the cumulative porosity distribution of the as-sprayed coating determined by mercury intrusion porosimetry. The diameters of all the surface connected pores are less than $100 \mu \mathrm{m}$. Fig. $7 \mathrm{~b}$ illustrates the compositions of porosity that are based on the result of the porosity measurement in Fig. 7a. The result reveals a typical bimodal pore size distribution. The pores with diameter ranged from about $0.1 \mu \mathrm{m}$ to about $3 \mu \mathrm{m}$ contribute a large percentage of the total porosity. These fine pores with a size smaller than $3 \mu \mathrm{m}$ are attributed to the small voids originated from gas entrapment, the microcracks and the micropores formed in

Table 2

The separated places of the specimens in the tensile test

\begin{tabular}{ll}
\hline Ceramic coating thickness & The separated place \\
\hline $0.2 \mathrm{~mm}$ & The glued interface \\
$0.3 \mathrm{~mm}$ & $\begin{array}{l}\text { The ceramic coating/bond coat } \\
\text { interface with a part of the glued interface } \\
\text { The ceramic coating/bond coat interface }\end{array}$ \\
$0.4 \mathrm{~mm}$ &
\end{tabular}




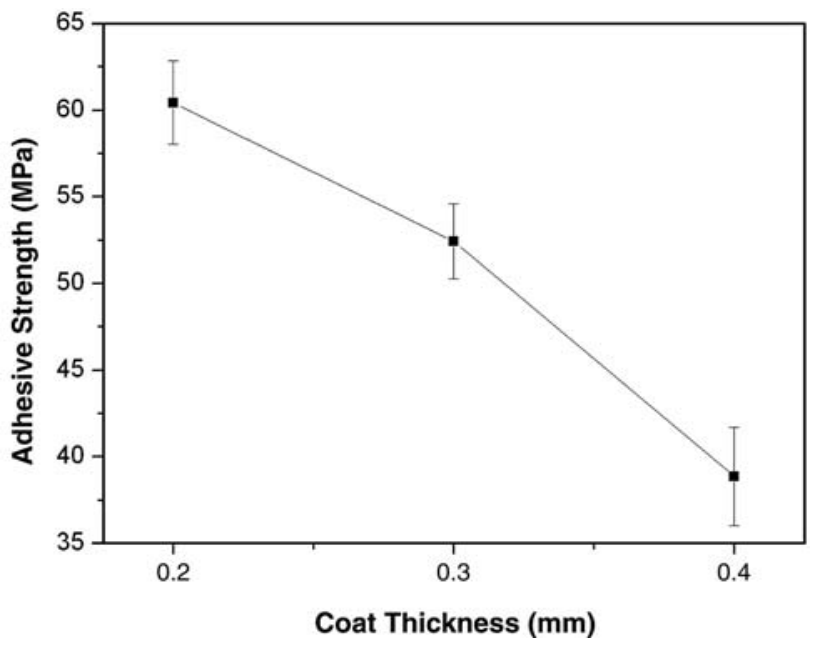

Fig. 8. The variation of the adhesive strength with the ceramic thickness. Error bars represent the standard deviations for all measured samples.

intersplats. The large defects corresponded to diameter above $3 \mu \mathrm{m}$ are the macropores between splats, resulted from poor adhesion. The pore distribution in the coating is relatively homogeneous. This result is in accordance with the SEM observation of the ceramic coating. The level of coating porosity is significantly connected with the spray conditions such as powder size, spray distance, spray angle, etc. The distribution and morphology of pores and microcracks are critical to the thermal conductivity and mechanical properties of the thermal barrier coatings. They interfere with the direct flow of heat, and result in lower thermal conductivity. The microcracks also increase the overall strain compliance of the coating, and hence, enhance the thermal shock resistance.

\subsection{The adhesive strength of the TBCs}

The successful application of plasma sprayed coatings to engineering usage depends on the adhesion between the coating and the substrate. The separated places of the specimens for the

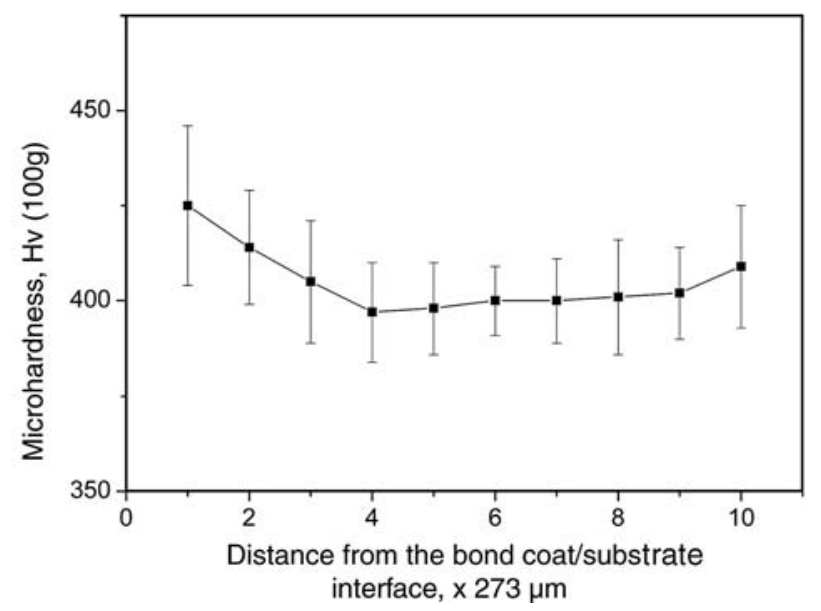

Fig. 9. The Vickers microhardness distribution along the thickness of the substrate after plasma spraying. Error bars represent the standard deviations for all measurements. tensile test are listed in Table 2. The specimens with $0.2 \mathrm{~mm}$ ceramic coating thickness are broken at the glued interface, which indicates that the measured value is lower than the real one. Some coatings peel off after drawing not wholly from the bond coat/ceramic coating interface, but partially from the inside of ceramic coating, which demonstrates that the ceramic coating has a good adhesion with the bond coat. All the specimens show a good bond status at the bond coat/substrate interface. The titanium alloy has a better adhesive strength with the bond coat than that of the ceramic coating with the bond coat. This is maybe caused by the difference of chemical properties between the ceramic and the metals. The variation of the adhesive strength with the ceramic coating thickness is shown in Fig. 8. The TBCs reveal a continuous decrease of the adhesive strength with increasing the thickness of as-sprayed ceramic coatings. This can be attributed to the residual thermal stresses induced during thermal spraying. The residual stresses increase with the increase of the ceramic coating thickness. A decrease of the adhesive strength, however, is related to a decrease of the spallation resistance under internal stresses.

a)

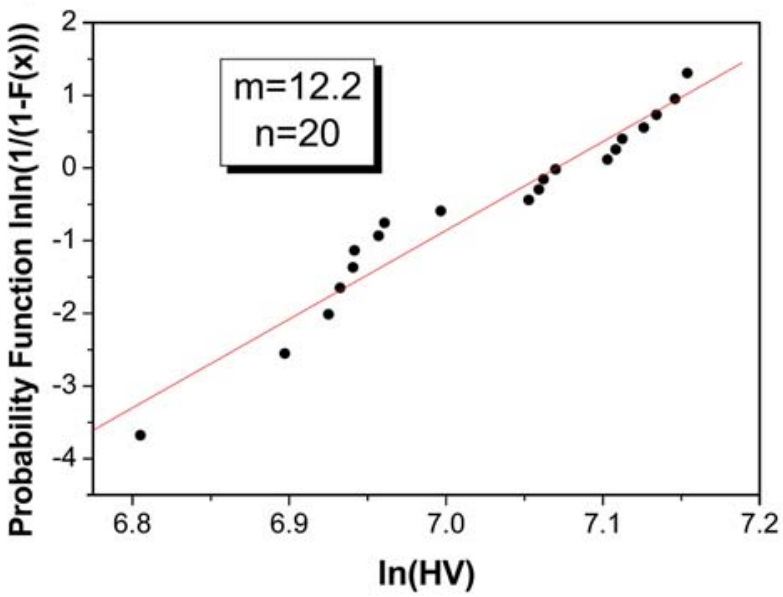

b)

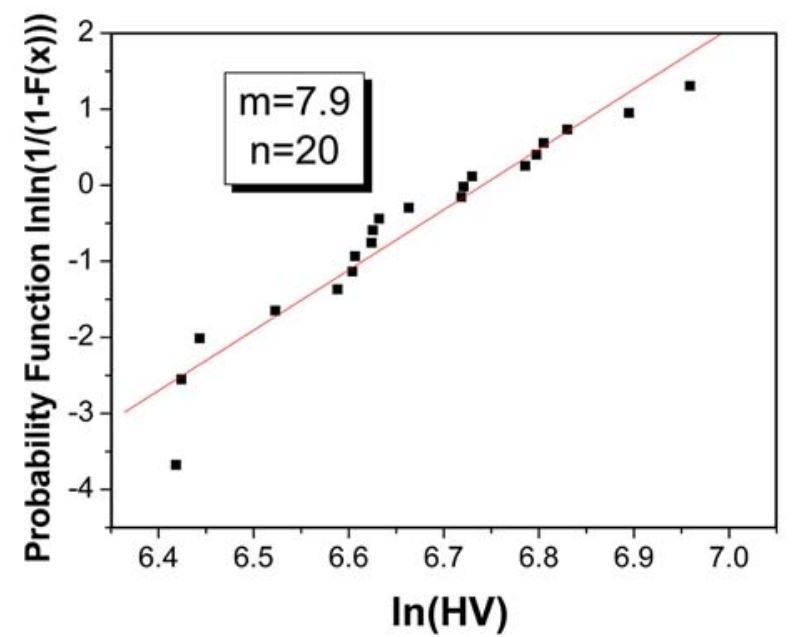

Fig. 10. Weibull plots of microhardness data within the ceramic coating for a) the cross section and $b$ ) the top surface. 
Table 3

Summary of the results obtained from the Weibull distribution plots

\begin{tabular}{llc}
\hline Ceramic position & Weibull modulus, $m$ & Hardness range in HV (ln (HV)) \\
\hline Cross section & 12.2 & $902-1279(6.80-7.15)$ \\
Top surface & 7.9 & $613-1052.5(6.42-6.96)$ \\
\hline
\end{tabular}

\subsection{Microhardness}

The mean values of microhardness at $100 \mathrm{~g}$ load for a dwell time of $15 \mathrm{~s}$ for the substrate before and after plasma spraying are $340 \pm 14 \mathrm{HV}$ and $405 \pm 32 \mathrm{HV}$, respectively. It is obvious that the microhardness of the substrate increases after plasma spraying. The microhardness difference for the substrate before and after plasma spraying reaches approximately $16 \%$. As discussed in the previous section, the residual stresses which form microcracks exist in the substrate. Accordingly the increased microhardness value of the substrate after spraying shows another evidence for the existence of residual stresses induced by the plasma spraying process. Fig. 9 presents the Vickers microhardness distribution after plasma spraying. The measurement points are evenly distributed along the thickness of the substrate. It can be seen that the microhardness values near the bond coat/substrate interface are obviously higher than that of the substrate inside. As we know that thermal stresses induced by thermal gradient and thermal expansion coefficients mismatch influence the substrate's mechanical properties, the area near the bond coat/substrate interface is affected by plasma spraying process directly, and the induced thermal stresses are concentrated in the area. Thus, the microhardness values in the area increased seriously. The microhardness values of the internal substrate were also influenced to get increased, but less than those near the interface. Moreover, the microhardness value near the naked surface is also slightly higher than that of the internal substrate after spraying. It may be explained that residual stresses induced by rapid cooling rate in the surface were responsible for this phenomenon.

The mean microhardnesses of 20 measurements at a $50 \mathrm{~g}$ load for a dwell time of $15 \mathrm{~s}$ for the ceramic coating are $1128 \pm$ $109 \mathrm{HV}$ on the cross section and $796 \pm 120 \mathrm{HV}$ on the top surface, respectively. The microhardness data show an explicit anisotropy in the mechanical properties between the cross section and the top surface of the as-sprayed ceramic coating. The lamellar structure is responsible for this phenomenon. The Weibull plots of the Vickers microhardness for the ceramic coating on the cross section and the top surface are shown in Fig. 10. The information provided by the figures is summarized in Table 3. It is evident that both the Weibull modulus values are good enough to show they have a satisfactory distribution. However, the Weibull modulus value, $m$, for the top coat is lower than that for the cross section. The low modulus corresponds to a high variability in the microhardness measurement. It may be caused by the splat structure formed by continuous wetting of liquid droplets during the plasma spraying. A flat splat with pancake shape is very thin in thickness. When the microhardness is measured on the cross section, the indentations are always taken place on several splats. Accordingly, the measured value is actually an average value which shows lower variability on those splats. Conversely, the microhardness measurement on the top surface, where there are many process-related defects in the form of interlamellar pores, microcracks and gas pores, reflects the data scattering obviously within the distribution.

\section{Conclusions}

Conventional thermal barrier coatings were applied on the titanium alloy by air plasma spraying. The microstructure of the titanium alloy inside the substrate keeps unchanged after plasma spraying. Neither interaction nor atomic diffusion evidently takes place at the bond coat/substrate interface. However, there exists a thin layer of plastic deformation zone in the substrate beneath the bond coat/substrate interface and its thickness is non-uniform. The as-sprayed ceramic coating consists of only the non-transformable tetragonal $\mathrm{t}^{\prime}$ phase of zirconia though the ceramic feedstock powder is composed of tetragonal and cubic and monoclinic phases. The surface connected porosity in the ceramic coating shows a typical bimodal pore size distribution. The adhesive strength of the TBCs decreases with increasing the thickness of as-sprayed ceramic coatings, which is attributed to the residual thermal stresses induced due to the temperature gradient and the mismatch of thermal expansion coefficient during thermal spraying. The anisotropy in the microhardness between the cross section and the top surface of the ceramic coating is examined because of the lamellar structure.

\section{Acknowledgements}

This research is sponsored by the Scientific Research Fund of Youth Teacher in Shanghai Jiao Tong University. The authors are grateful to Mr. Y. Lai, the instrumental analysis center, Shanghai Jiaotong University for the help with sample examination and helpful discussion.

\section{References}

[1] S. Becker, A. Rahmel, M. Schorr, M. Schutze, Oxid. Met. 38 (1992) 425.

[2] C. Leyens, R. Braun, M. Fröhlich, P. Hovsepian, JOM 58 (2006) 17.

[3] D.W. Mckee, K.L. Luthra, Surf. Coat. Technol. 56 (1993) 109.

[4] H.P. Liu, S.S. Hao, X.H. Wang, Scr. Mater. 39 (1998) 1443.

[5] C. Tao, Q. Liu, C. Chao, W. Zhang, Failure and Prevention of Aeronautical Titanium Alloy, National Defense Industry Press, Beijing, 2002, p. 9 (in Chinese).

[6] N.P. Padture, Maurice Gell, E.H. Jordan, Science 296 (2002) 280.

[7] R.A. Miller, J. Therm. Spray Technol. 6 (1997) 35.

[8] G.W. Goward, Surf. Coat. Technol. 108-109 (1998) 73.

[9] R. Braun, C. Leyens, M. Fröhlich, Mater. Corros. 56 (2005) 930.

[10] Z. Tang, F. Wang, W. Wu, Surf. Coat. Technol. 99 (1998) 248.

[11] N. Orlovskaja, H. Peterlink, M. Marczewski, J. Mater. Sci. 32 (1997) 1903.

[12] C.K. Lin, C.C. Berndt, J. Mater. Sci. 30 (1995) 111.

[13] R.S. Lima, A. Kucuk, C.C. Berndt, Mater. Sci. Eng. A327 (2002) 224.

[14] H.G. Scott, J. Mater. Sci. 10 (1975) 1527.

[15] Editing committee, Practical Handbook for Engineering Material, China Machine Press, Beijing, 1989, p. 7 (in Chinese). 